\title{
The End of The American Network
}

Can the Internet be liberated from government meddling?

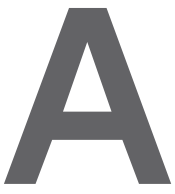

S DETAILS of the U.S. National Security Agency's (NSA) pervasive phone and Internet eavesdropping and surveillance operations emerged last summer, sales of George Orwell's classic novel, 1984, were reported to have risen dramatically. Orwell described an oppressive government that continually monitors the population through ever-present "telescreens." A recent newspaper article proclaimed that "NSA surveillance programs greatly exceed anything the 1984 author could have imagined."

Indeed, what we have learned so far about the wide reach of the NSA's operations has been quite astounding. First, we learned the NSA is collecting on an ongoing basis phone records of essentially all U.S. telecommunications customers. Second, we learned the NSA monitors all Internet traffic that goes through U.S. telecommunications infrastructure. Third, we learned the NSA has intentionally weakened cryptographic standards to enable it to circumvent encryption. All of this has been authorized by secret court orders. In essence, we learned the U.S. government has stretched the meaning of "reasonable" in the U.S. Constitution Bill of Right's proscription against unreasonable searches beyond reasonableness. NSA, indeed, is certainly making Orwell's surveillance technology seem rather primitive in comparison.

The unfolding scandal reminds me of another aspect of Orwell's novel. The language spoken in Oceania, the novel's fictional country, is "Newspeak," whose grammar is based on English, but whose vocabulary is tightly controlled in an effort to limit free thought. When NSA Director James
Clapper was asked, following this summer's revelations, to explain his answers given in U.S. Congress testimony earlier in the spring, he replied: "I responded in what I thought was the most truthful, or least untruthful manner." I have no doubt that Orwell would have been proud to add the phrase "least untruthful manner" to the vocabulary of Newspeak. Granted, NSA is, after all, an intelligence agency, and countries do spy on each other (at their own risk!), but the NSA is not supposed to be a domestic intelligence agency and it is not supposed to lie to the U.S. Congress!

This phrase "least untruthful manner" symbolizes for me the most disturbing aspect of the NSA scandal. The U.S. government, supposedly "of the people, by the people, for the people," to quote Abraham Lincoln's Gettysburg Address, has been untruthful to its citizens for several years and has been coercing many U.S. corporations that operate phone and Internet infrastructure to be equally untruthful. An old joke asks: "How can you tell when a lawyer is lying?" Answer: "His lips are moving." There is no need anymore to pick on lawyers; we can substitute "NSA official" in the joke. Our trust in the U.S. government and U.S. corporations has been broken. It is unlikely to be repaired in the near future.

This means, I believe, we can no longer trust the U.S. government to be the "Internet hegemon." During the 1990s, when the Internet was rising while Minitel, the French phone-based online service, was declining (it was finally retired in 2012), France's President Jacques Chirac complained about rising dominance of the Internet, which he described as "the American Internet." While many of us snickered at his provinciality, Chirac was right. The National Telecommunications and Information Administration, an agency of the U.S. Department of Commerce, continues to have final approval over changes to the DNS root zone. Thus, in spite of its being a globally distributed system, the Internet is ultimately controlled by the U.S. government. This enables the U.S. government to conduct Internet surveillance operations that would have been impossible without this degree of control.

The main argument in favor of the privileged position of the U.S. government in Internet governance is that other governments, which have been clamoring for true internationalization of Internet governance, perhaps through the International Telecommunication Union, were viewed as less trustworthy than the U.S. government. With the trustworthiness of the latter in serious decline due to the NSA scandal, voices are rising again in protest of U.S. Internet hegemony. The question being raised is "Can there be a non-U.S. Internet?" In fact, Brazil has already laid out a multipoint plan to sever ties with U.S.-controlled cyberspace.

But replacing U.S. hegemony with hegemony by other governments, who may not only have their own surveillance operations but also attempt to regulate content and restrict free expression on the Internet, hardly seems an improvement to me. The real question, I believe, is whether we can have an Internet that is free, or at least freer, from government meddling than today's Internet. In view of the Internet's centrality in our information-saturated lives, this is a question of the utmost importance.

Moshe Y. Vardi, EDITOR-IN-CHIEF 